\title{
Integrating agroecological production in a robust post-2020 Global Biodiversity Framework
}

To the Editor - The 15th Conference of the Parties (COP) meeting to the Convention on Biological Diversity in China - now to be held in 2021 due to the coronavirus pandemic - will provide new opportunities for biodiversity conservation (https://go.nature.com/31YAVNF) through the decision on the post-2020 Global Biodiversity Framework (GBF). In short, the GBF is a global and solution-oriented framework aiming for transformative action by governments, civil society and businesses, to help biodiversity recover for the benefit of people and planet ${ }^{1}$. Agriculture is the most extensive form of land use, occupying more than one-third of the global landmass, and imperilling $62 \%$ of all threatened species globally ${ }^{2}$. Habitat conversion and conventional farming practices - including heavy use of agrochemicals - have negative effects on biodiversity ${ }^{3}$, even spilling into protected areas. However, if designed appropriately, agricultural landscapes can provide habitats for biodiversity, promote connectivity between protected areas, and increase the capacity of species to respond to environmental threats ${ }^{4,5}$. While halting the loss of protected and intact nature is essential to halt species loss, bending the curve on biodiversity will require sustainable agriculture. We argue that the GBF must include conservation actions in agricultural landscapes based on agroecological principles (sensu High Level Panel of Experts ${ }^{6}$ ) in the three ' 2030 Action Targets' (hereafter 'Targets') to reach its goals of biodiversity recovery. Agroecology is widely recognized as a necessary transformation in order to achieve food system sustainability.

\section{Agroecological principles in the post- 2020 Global Biodiversity Framework} Below, we elaborate on how agroecological production can help to support the GBF targets.

\section{Target 1 - reduce the threats to} biodiversity. Comprehensive spatial planning for diversified agriculture benefits biodiversity conservation and nature's contributions to people (NCP $)^{7,8}$, when integrating multiple spatial scales from local to regional and multi-stakeholder participatory approaches. Diversified farmlands enhance biodiversity, biocontrol,

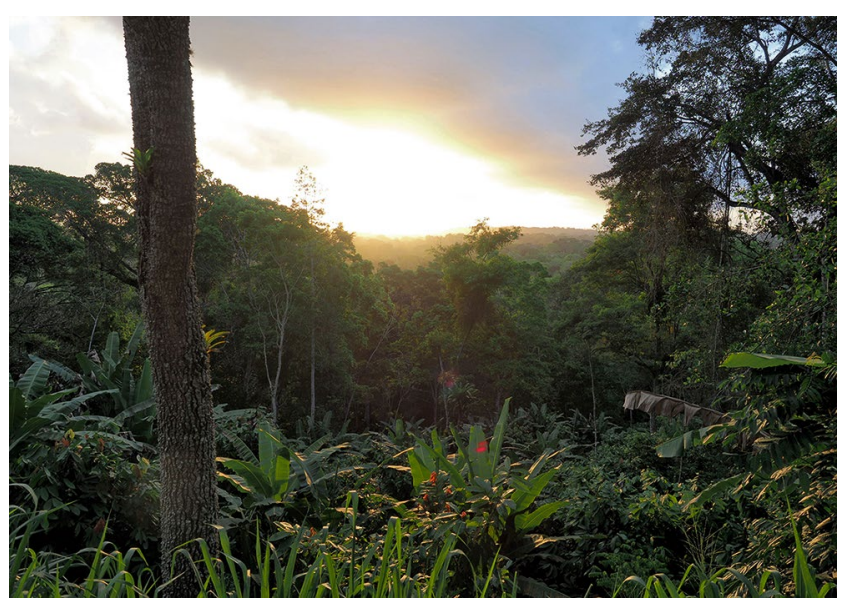

Cocoa agroforestry systems (Cabrucas) in Bahia, Brazil are an example for biodiversity-friendly cocoa production based on agroecological principles. Credit: Thomas Cherico Wanger

pollination and reduce pathogen and pest impact ${ }^{7}$, thereby contributing to achieve conservation objectives in proximate protected areas, as more protected areas are seeing impact in intensive land use in surrounding areas ${ }^{9}$. Agroecological practices can considerably reduce the use of synthetic pesticides $^{10}$, a major cause of biodiversity loss $^{11}$. A more effective use of fertilizers can reduce nutrient pollution and mitigate climate impacts by maintaining healthier, carbon-sequestering soil microbiota ${ }^{12}$. Diversified cropping systems can further mitigate greenhouse gas emissions by, for example, non-crop tree diversification in agroforestry systems, thereby enhancing agrobiodiversity benefits ${ }^{13,14}$.

Target $2-$ meeting people's needs through sustainable use and benefit sharing. Agroecological production is a comprehensive framework for the sustainable use of biodiversity that also supports productivity and resilience ${ }^{15}$. Farmers benefit from diversified systems through increased economic resilience, reduced dependency on agrochemical inputs, and in subsistence systems more diverse and nutritious foods ${ }^{16-18}$. Moreover, agroecological production can reduce negative externalities and off-farm inputs, while increasing biodiversity and $\mathrm{NCP}^{19,20}$. Trade-offs between agroecological approaches and yield are often assumed, but not inherent ${ }^{21}$. New crop varieties, crop combinations and technological innovations will only further reduce yield gaps between conventional and agroecological production $^{19,22}$, when the availability is fair and locally appropriate.

Target $3-$ tools and solutions for implementation and mainstreaming. Eco-certification and agricultural policies - if well informed and implemented - provide important opportunities to encourage diversified farm and landscape measures for conservation ${ }^{23,24}$. Corporate and government commitments to zero-deforestation and eco-labelling could be enhanced by coupling production and protection goals within innovative investment models that emphasize natural assets. Investing in diversified systems can mitigate environmental vulnerability by embedding resilience into supply chains ${ }^{25}$. Promotion and equitable participation of indigenous peoples and local communities in decision-making processes is critical to incorporate their perspective on and knowledge about agroecological approaches. Lastly, an understanding of agroecological production, benefits for biodiversity conservation, food security, and overall better quality of life can help to shape new social norms for sustainability ${ }^{6}$. 
Box 1 | A research agenda for agroecology

1. Reducing threats to biodiversity.

- Develop agricultural systems whereby negative externalities outside farms and (organism) spillover effects in protected areas are internalized so that the producer bears the costs of negative impacts.

- Integrative conservation management strategies of farmlands surrounding protected areas.

- Build integrated and scalable models for agroecological production to quantify field-, farm- and landscape-level effects on socioecological systems.

- Enhance global integration of existing and new data through global research networks.

- Expand the use of technological innovations in agroecological production to reduce impacts on biodiversity.

- Set up (further) large-scale and long-term experiments in agroecological production systems to monitor the interaction between farm and landscape diversification effects on socioecological systems.
2. Addressing people's needs and benefit sharing.

- Foster research that ensures access to sufficient nutritious and healthy food for all.

- Assess farm-level diversity effects on food security and food sovereignty in different countries.

- Establish effective communication with farmers and incentive approaches for them to utilize in agroecological production.

- Determine and then further improve the relationships between biodiversity changes and economic value in agroecological production systems through effective land-use planning.

- Quantify the effects of agroecological practices on multi-dimensional aspects (for example, health, happiness and profitability) of good quality of life, and their potential synergies and trade-offs.

- Understand the long-term effects of agroecological and conventional farming practices.
3. Providing tools and solutions for implementation and mainstreaming.

- Assess multi-scale effects of eco-certification encouraging agroecological production on biodiversity and socioecological systems.

- Understand social, power and value barriers on the local scale to facilitate a global transition from conventional to agroecological production systems.

- Develop a new set of indicators for local to global application to measure comprehensive agricultural systems performance beyond production.

- Quantify diversification effects on supply chain actors; specifically, understand the costs of smaller amounts of more products on livelihoods of small-scale producers.

- Identify obstacles to include diversification along supply chains.

- Determine effects of supply chain transparency and investment accountability on stakeholder empowerment.

- Assess the effects of agroecological production on ecosystem service enhancement and local and global markets.

\section{A way forward for the post-2020 Global Biodiversity Framework and agroecology}

A global transition from conventional to agroecological production will be critical to achieve the action targets and meet the GBF goals. Diversification at the field, farm and landscape scale holds large promises to make food systems more sustainable; however, farmers alone cannot achieve this major transformation. Action is required across the entire supply chain, from the processing industry to distributors to the consumers. Future research on agroecological production (Box 1) needs to (1) depart from traditional research approaches and increasingly engage in multi-stakeholder networks to define options that work in practice and across scales; (2) build on 'theories of change' and indicators to develop actionable strategies and quantify change; (3) support policy makers through easily accessible advisory services to promote change in the wider socioecological landscape, incentivize local innovation systems and increase budget allocations for agroecological transition; and (4) enable public and private funding for long-term research programmes more apt for the timescales that agroecological interventions operate on. By integrating agroecological principles and related future research, the GBF will be more robust in considering threats to biodiversity, people's needs and identifying tools and solutions in support of its 2050 vision of 'Living in harmony with nature?

\section{Thomas C. Wanger (1),2,3凶,}

Fabrice DeClerck ${ }^{4,5}$, Lucas A. Garibaldi (0) 6,7 , Jaboury Ghazoul (1) 8,9,10, David Kleijn (1011,

Alexandra-Maria Klein ${ }^{12}$, Claire Kremen (10) ${ }^{13}$, Harold Mooney ${ }^{14}$, Ivette Perfecto (D) 15, Luke L. Powel|16,17, Josef Settele ${ }^{18,19,20,}$ Mirco Solé (1) 21, Teja Tscharntke ${ }^{2}$ and Wolfgang Weisser (1D 22

${ }^{1}$ Sustainability, Agriculture and Technology Laboratory, School of Engineering, Westlake University, Hangzhou, China. ${ }^{2}$ Agroecology, University of Göttingen, Göttingen, Germany. ${ }^{3}$ GlobalAgroforestryNetwork.org, Hangzhou, China. ${ }^{4}$ EAT Forum, Oslo, Norway. ${ }^{5}$ Alliance of Bioversity \& CIAT, CGIAR, Montpellier, France. ${ }^{6}$ Instituto de Investigaciones en Recursos Naturales, Agroecología y Desarrollo Rural, Universidad Nacional de Río Negro, Río Negro, San Carlos de Bariloche, Argentina. ${ }^{7}$ Consejo Nacional de Investigaciones Científicas y Técnicas, Instituto de Investigaciones en Recursos Naturales, Agroecología y Desarrollo Rural, Río Negro, Argentina. ${ }^{8}$ Department of Environmental Systems Science, ETH Zurich, Zurich, Switzerland. ${ }^{9}$ Centre for Sustainable Forests and Landscapes,
School of Geosciences, University of Edinburgh, Edinburgh, UK. ${ }^{10}$ Ecology and Biodiversity Group, Utrecht University, Utrecht, The Netherlands.

${ }^{11}$ Plant Ecology and Nature Conservation Group, Wageningen University, Wageningen, Netherlands.

$\square \quad{ }^{12}$ Faculty of Environment and Natural Resources, University of Freiburg, Freiburg, Germany. ${ }^{13}$ Institute for Resources, Environment and Sustainability, University of British Columbia, Vancouver, British Columbia, Canada. ${ }^{14}$ Department of Biology, Stanford University, Stanford, CA, USA. ${ }^{15}$ School for Environment and Sustainability, University of Michigan, Ann Arbor, MI, USA. ${ }^{16}$ Institute for Biodiversity, Animal Health, and Comparative Medicine, University of Glasgow, Glasgow, UK. ${ }^{17}$ Department of Biosciences, Durham University, Durham, UK. ${ }^{18}$ Department of Community Ecology, Helmholtz Centre for Environmental Research - UFZ, Halle, Germany. ${ }^{19}$ German Centre for Integrative Biodiversity Research (iDiv) Halle-Jena-Leipzig, Leipzig, Germany. ${ }^{20}$ Institute of Biological Sciences, University of the Philippines Los Baños, Laguna, Philippines. ${ }^{21}$ Department of Biological Sciences, Universidade Estadual de Santa Cruz, Ilhéus, Brazil. ${ }^{22}$ Department for Ecology and Ecosystem Management, Technical University Munich, Munich, Germany.

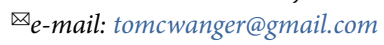

Published online: 20 July 2020

https://doi.org/10.1038/s41559-020-1262-y 


\section{References}

1. Zero Draft of the Post-2020 Global Biodiversity Framework (CBD, 2020); https://go.nature.com/3iNT06T

2. Maxwell, S. L., Fuller, R. A., Brooks, T. M. \& Watson, J. E. M. Nature 536, 143-145 (2016).

3. Köhler, H.-R. \& Triebskorn, R. Science 341, 759-765 (2013).

4. Kremen, C. \& Merenlender, A. M. Science 362, eaau6020 (2018)

5. Perfecto, I., Vandermeer, J. H. \& Wright, A. L. Nature's Matrix: Linking Agriculture, Conservation and Food Sovereignty (Routledge, 2009).

6. Agroecological and other Innovative Approaches for Sustainable Agriculture and Food Systems that Enhance Food Security and Nutrition (HLPE, 2019).

7. Tscharntke, T., Klein, A. M., Kruess, A., Steffan-Dewenter, I. \& Thies, C. Ecol. Lett. 8, 857-874 (2005).

8. Dainese, M. et al. Sci. Adv. 5, eaax0121 (2019).

9. Häkkilä, M. et al. PLoS ONE 12, e0184792 (2017).

10. Gurr, G. M. et al. Nat. Plants 2, 16014 (2016).

11. Hallmann, C. A. et al. PLoS ONE 12, e0185809 (2017).

12. Sutton, M. A. et al. The European Nitrogen Assessment: Sources, Effects and Policy Perspectives (Cambridge Univ. Press, 2011).
13. Tscharntke, T. et al. J. Appl. Ecol. 48, 619-629 (2011).

14. Wanger, T. C., Hölscher, D., Veldkamp, E. \& Tscharntke, T. Glob. Change Biol. 24, 561-562 (2018).

15. Tscharntke, T. et al. Biol. Conserv. 151, 53-59 (2012).

16. Rosa-Schleich, J., Loos, J., Mußhoff, O. \& Tscharntke, T. Ecol. Econ. 160, 251-263 (2019).

17. Sibhatu, K. T. \& Qaim, M. Food Policy 77, 1-18 (2018).

18. Renard, D. \& Tilman, D. Nature 571, 257-260 (2019).

19. Kremen, C. \& Miles, A. Ecol. Soc. 17, 40 (2012).

20. Luke, S. H. et al. J. Appl. Ecol. 56, 85-92 (2019).

21. Garbach, K. et al. Int. J. Agric. Sustain. 15, 11-28 (2017).

22. Finger, R., Swinton, S. M., El Benni, N. \& Walter, A. Annu. Rev. Resour. Econ. 11, 313-335 (2019).

23. Tscharntke, T. et al. Conserv. Lett. 8, 14-23 (2015).

24. Pe’er, G. et al. Science 344, 1090-1092 (2014).

25. Löfquist, S. \& Ghazoul, J. Nat. Ecol. Evol. 3, 1612-1615 (2019).

\section{Acknowledgements}

366 signatories from 42 countries support and agree with this Correspondence. The full list of signatories and their affiliations appears in the Supplementary Information. Many signatories provided valuable comments that improved the final document.

\section{Author contributions}

T.C.W. initiated the idea, wrote the initial draft, and coordinated the sign up to the 'List of Signatories'. T.C.W., F.D.C., L.A.G., J.G., D.K., A.-M.K., C.K., H.M., I.P., L.L.P., J.S., M.S., T.T. and W.W. discussed and refined the manuscript and distributed the document through their networks.

\section{Competing interests}

The authors declare no competing interests.

\section{Additional information}

Supplementary information is available for this paper at https://doi.org/10.1038/s41559-020-1262-y. 